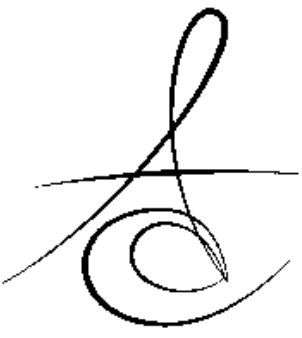

Arş. Gör. Dr. Taha ÖZYÜREK*

\section{REHBER YOLU OLUŞTURULMASINDA FARKLI EĞE SİSTEMLERİNİN ETKİNLİKLERİNİN KARŞILAŞTIRILMASI}

\section{COMPARISON OF EFFECT OF DIFFERENT FILE SYSTEMS ON GLIDE PATH CREATION}

\author{
Arş. Gör. Koray YILMAZ*
}

\section{öz}

Amaç: Farklı nikel-titanyum döner rehber yol eğelerinin şekillendirme etkinliklerinin J şekilli yapay kanallarda değerlendirilmesi.

Gereç ve Yöntem: Otuz adet J şekilli kanallara sahip rezin blok PathFile, ProGlider ve manuel eğeler ( $n$ : 10 kanal/grup) kullanılarak şekillendirildi. Şekillendirme öncesi ve sonrası elde edilen fotoğraflar dijital ortamda üst üste getirilerek çakıştırılmış görüntüler elde edildi. Eğeler tarafından uzaklaştırılan rezin miktarı dijital ölçüm kalıbı ve fotoğraf analiz programı kullanılarak ölçüldü. Kanal düzensizlikleri de kayıt edildi. Elde edilen veriler tek yönlü varyans analizi ve post hoc Tukey testi kullanılarak istatistiksel olarak analiz edildi. Bulgular: Eğelerin uzaklaştırdığı rezin miktarları arasında gruplar arasında istatistiksel fark bulunmadı $(P>0,05)$. Kanal şekillendirmesi sırasında manuel eğe grubunda 1 örnekte basamak oluşumu gözlendi.

Sonuç: Çalışmamızın sınırları dahilinde test edilen PathFile, ProGlider ve manuel eğelerin 5 farklı ölçüm noktasında göstermiş olduğu sapmalar arasında fark bulunamamıştır.

Anahtar Kelimeler: Endodonti; Nikel-Titanyum; PathFile; ProGlider; Rehber Yol

\section{GİRİŞ}

Kök kanal şekillendirmesi öncesi rehber yol oluşturulması, nikel-titanyum (NiTi) döner eğe sistemlerinin güvenli kullanımı için ilk adım olarak kabul edilir. Bu işlem şekillendirme sırasında oluşabilecek hataları, alet kırılmalarını ve aletlerin kanalda maruz kaldığı vidalanma etkisini azaltır. ${ }^{1-4}$ Ayrıca yeterli burulma direncine sahip olan rehber yol eğeleri, kanal ağız-

\section{ABSTRACT}

Aim: To evaluate the shaping ability of different glide path rotary nickel-titanium files in simulated J-shaped canals.

Material and Methods: Thirty J-shaped canals in resin blocks were prepared using PathFile, ProGlider or manual files ( $n$ : 10 canals/group). Composite images were made from the superimposition of pre- and postinstrumentation images in digital platform. The amount of resin removed by each system was measured by using a digital template and image analysis software. Canal aberrations were also recorded. The data were statistically analyzed by using one-way ANOVA and post hoc Tukey test.

Results: There was no significantly difference between groups according to the amount of resin removal $(P>0.05)$. One ledge formation was inspected during canal preparation in manual group.

Conclusions: Within the limitation of the present study, there was no significant difference among PathFile, ProGlider and manual file groups in 5 different measurement points

Keywords: Endodontics; Nickel-Titanium; PathFile; ProGlider; Glide Path

de kolaylık sağlar. ${ }^{5}$ Bu amaçla Blum ve ark., NiTi döner aletlerin kök kanallarında kolayca takip edebileceği yol oluşturmak için küçük boyutlarda manuel paslanmaz çelik eğeler ile rehber yol oluşturulmasını önermişlerdir. ${ }^{6}$ Yapılan çalışmalarda, döner NiTi eğe sistemlerinin kullanımından önce rehber yol oluşturulmasının kök kanal anatomisini daha iyi koruduğu bildiri miştir. ${ }^{7,8}$

\footnotetext{
* Ondokuz Mayıs Üniversitesi Diş Hekimliği Fakültesi, Endodonti Anabilim Dall, Samsun
} 
NiTi rehber yol döner alet sistemi ilk olarak Dentsply Maillefer (Ballaigues, İsviçre) firması tarafından PathFile sistemi adı ile piyasaya sürülmüştür. Sistem kare kesiti ve 0.02 sabit taper açısıyla 3 adet eğeden oluşmaktadır. PathFile $10,13 \mathrm{~mm}$ uç çapına, PathFile 2 0,16 mm, PathFile 3 de 0,19 mm uç çapına sahiptir. $^{2} \mathrm{NiTi}$ eğelerin üretildiği alaşımlarda ortaya çıkan gelişmelerle beraber, eğelerin döngüsel yorgunluk direncinde de artış sağlanmıştır. Ayrıca kök kanal şekillendirmesini kolaylaştırmak ve şekillendirme süresini kısaltmak amacıyla yeni nesil tek eğe NiTi rehber yol döner eğe sistemleri geliştirilmiştir. ProGlider (Dentsply Maillefer) ısıl işlem görmüş M-Wire alaşımdan üretilen rehber yol döner eğe sistemidir. ProGlider kare kesitiyle birlikte dört kesici kenara sahiptir ve diğer döner rehber yol eğe sistemlerinden farklı olarak şaftı boyunca \%2'den \%8'e kadar değişen koniklik açısına ve $0,16 \mathrm{~mm}$ uç çapına sahiptir. ${ }^{9}$

Bu çalışmanın amacı rehber yol oluşturmak için kullanılan manuel paslanmaz çelik eğeler, konvansiyonel NiTi alaşımdan üretilmiş PathFile ve M-Wire alaşımdan üretilmiş ProGlider rehber yol eğe sistemlerinin J şekilli yapay akrilik bloklarda şekillendirme etkinliklerinin değerlendirilmesidir. Çalışmamızın sıfır hipotezi ise, test edilen eğelerin şekillendirme etkinlikleri açısından fark olmayacağıdır.

\section{GEREÇ VE YÖNTEM}

Çalışmamızda 30 adet 0,02 koniklik açısına, $0,15 \mathrm{~mm}$ apikal çapa ve $16 \mathrm{~mm}$ çalışma boyuna sahip J şekilli yapay kanal (Endo Training Block; Dentsply Maillefer, Ballaigues, İsviçre) kullanıldı. Yapay kanalların kanal açıkıkları \#10 K-file (Dentsply Maillefer) ile kontrol edildikten sonra rastgele 3 gruba ( $n: 10)$ ayrilarak aşağıdaki işlemeler uygulandı:

\section{Grup 1: Manuel Eğe}

Bu grupta bulunan blokların kanallarında rehber yol, \#10, \#15 ve \#20 numaralı K-tipi manuel eğeler (Dentsply Maillefer) yardımıyla oluşturuldu.

\section{Grup 2: PathFile}

Bu grupta bulunan blokların kanallarında rehber yol, PathFile sisteminin sırasıyla 1,2 ve 3 numaralı eğeleri, tork kontrolü endodontik motor (X-Smart, Dentsply Maillefer) yardımıyla $300 \mathrm{rpm}$ ve $5 \mathrm{Ncm}$ tork değerinde kullanılarak oluşturuldu.

\section{Grup 3: ProGlider}

Bu grupta bulunan blokların kanallarında rehber yol, ProGlider eğesi ile crown-down tekniğine uygun olarak, tork kontrolü endodontik motor (X-Smart) yardımıyla $300 \mathrm{rpm}$ ve $5 \mathrm{Ncm}$ tork değerinde kullanılarak oluşturuldu.

Bütün işlemler NiTi eğelerin kullanımı konusunda deneyimli bir endodontist tarafindan uygulandı. Her kanalın şekillendirilmesi için yeni eğe kullanıldı. Eğelerin kullanımı sırasında kanallar toplam $20 \mathrm{ml}$ distile su ile irrige edildi. Toplamda 30 adet J şekilli yapay kanal şekillendirildi.

Yapay Kanalların Şekillendirilmesinin Değerlendirilmesi

Şekillendirme işlemine başlamadan önce bütün kanallar siyah mürekkep (Pelikan, İstanbul, Türkiye) ile boyandı. Daha sonra kanalların standart bir düzeneğe adapte edilmiş fotoğraf makinesi (Canon EOS 500D, Japonya) yardımılla fotoğrafları alındı. Kanallara ilgili şekillendirme işlemleri uygulandıktan sonra kanallar kırmızı mürekkep (Pelikan) ile boyandıktan sonra aynı düzenek kullanılarak tekrar fotoğrafları alındı.

Kanalların işlem öncesi ve sonrası fotoğrafları bilgisayar programı kullanılarak (Pages; Apple Inc., Cupertino, $C A, A B D$ ) üst üste getirilerek çakıştırılmış görüntüler elde edildi. Aynı program vasıtasıyla bu çakıştırımış görüntülerin üzerine ölçüm için hazırlanmış kalıp yerleştirildi (Şekil 1). Daha sonra görüntüler AutoCAD (Autodesk, San Rafael, CA, ABD) programına aktarılarak toplamda 10 noktada (5 iç kısım, 5 dış kısım) kanaldan uzaklaştııılan rezin miktarının ölçümü gerçekleştirildi. Ölçüm noktaları olarak; kanal girişi $(K G)$, kanalın düz kısmındaki kanal ağzından olan mesafenin yarısı (kanal girişinin yarısı) (KGY), kurvatürün başlangıcı (KB), kurvatürün sonu (KS), apeks noktası (AN) belirlendi. ${ }^{10,11}$

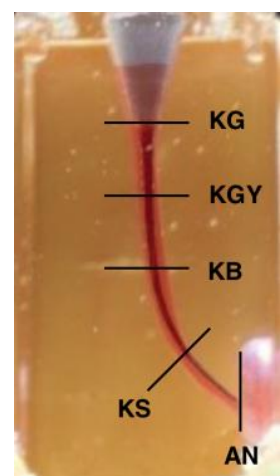

Şekil 1. Pages (Apple Inc., Cupertino, CA, ABD) programı kullanılarak kanalların işlem öncesi ve sonrası fotoğraflarının çakıştırılması ve kullanılan ölçüm noktaları (kanal girişi (KG), kanalın düz kısmındaki kanal ağzından olan mesafenin yarısı (kanal girişinin yarısı) (KGY), kurvatürün başlangıCı (KB), kurvatürün sonu (KS), apeks noktası (AN)).

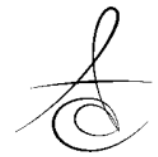


Elde edilen verilen analizi SPSS 21 (IBM-SPSS Inc., Chicago, IL, ABD) programı kullanılarak yapıldı. Elde edilen verilen normal dağılım gösterdiği ShapiroWilk testi ile belirlendi. Gruplar arasında fark tek yönlü varyans analizi ve post hoc Tukey testi yardımı ile incelendi. İstatistiksel önem seviyesi \%5 olarak belirlendi.

\section{BULGULAR}

Preperasyon sonrası kanalların ortalama genişliklerinin gruplara göre dağılımı Tablo 1'de gösterilmektedir. Preperasyon sonrası kanalların iç ve dış kısımlardan uzaklaştırılan ortalama rezin miktarları Tablo 2'de gösterilmektedir.

Ölçüm yapılan 5 noktada preperasyon sonrası kanalların sahip olduğu ortalama genişlikler açısından gruplar arasında istatistiksel olarak fark bulunmamıştır $(P>0,05)$.

Sadece manuel eğe grubunda 1 örnekte basamak oluşumu gözlenmiş olup diğer gruplarda herhangi bir kanal içi düzensizlik tespit edilememiştir.

Tablo 1. Yapay kanalların preperasyonu sonrası ortalama genişlikleri (mm).

\begin{tabular}{lccc}
\hline Kanal Lokalizasyonu & ProGlider & PathFile & Manuel Eğe \\
\hline Kanal Girişi (KG) & 0,60 & 0,52 & 0,44 \\
\hline Kanal Girişinin Yarısı (KGY) & 0,55 & 0,45 & 0,40 \\
\hline Kurvatürün Başlangıcı (KB) & 0,39 & 0,38 & 0,33 \\
\hline Kurvatürün Sonu (KS) & 0,30 & 0,35 & 0,28 \\
\hline Apeks Noktası (AN) & 0,25 & 0,32 & 0,26 \\
\hline *Gruplar arasında istatistiksel fark yoktur $(P<0,05)$.
\end{tabular}

Tablo 2. Yapay kanalların şekillendirilmesi sonrasında ölçüm noktalarında kanalların iç ve dış taraflarından kaldırılan ortalama rezin miktarları $(\mathrm{mm})$.

\begin{tabular}{|c|c|c|c|c|c|c|c|c|c|c|}
\hline & \multicolumn{2}{|r|}{ KG } & \multicolumn{2}{|c|}{ KGY } & \multicolumn{2}{|c|}{ KB } & \multicolumn{2}{|l|}{ KS } & \multicolumn{2}{|c|}{ AN } \\
\hline & İç & Dış & İ́ç & $\begin{array}{l}\text { DI } \\
\text { ş }\end{array}$ & İç & Dış & İç & $\begin{array}{l}\text { DI } \\
\text { s }\end{array}$ & İç & Dış \\
\hline ProGlider & $0,04^{a}$ & $0,06^{x}$ & $0,07^{\mathrm{a}}$ & $0,08^{x}$ & $0,05^{\mathrm{a}}$ & $0,02^{x}$ & $0,02^{\mathrm{a}}$ & $0,01^{x}$ & $0,01^{\mathrm{a}}$ & $0,01^{x}$ \\
\hline PathFile & $0,03^{b}$ & $0,06^{x}$ & $0,06^{\mathrm{b}}$ & $0,06^{y}$ & $0,04^{b}$ & $0,03^{y}$ & $0,03^{b}$ & $0,02^{y}$ & $0,02^{\mathrm{b}}$ & $0,03^{y}$ \\
\hline $\begin{array}{l}\text { Manuel } \\
\text { Eğe }\end{array}$ & $0,03^{b}$ & $0,04^{y}$ & $0,05^{c}$ & $0,04^{y}$ & $0,01^{c}$ & $0,03^{y}$ & $0,02^{\mathrm{a}}$ & $0,01^{x}$ & $0,01^{\mathrm{a}}$ & $0,02^{2}$ \\
\hline$P$ değeri & $<0,05$ & $<0,05$ & $<0,05$ & $<0,05$ & $<0,05$ & $5<0,05$ & $<0,05$ & $<0,05$ & $<<0,05$ & $<0,05$ \\
\hline
\end{tabular}

\section{TARTIŞMA}

Kök kanal şekillendirmesinden önce rehber yol oluşturulması şekillendirme sırasında NiTi eğelerin güvenli bir şekilde kullanılabilmesi için oldukça önemlidir. ${ }^{12}$ Ancak ön genişletme ve rehber yol oluşturulması aşamasında basamak oluşumu gibi kanal içi düzensizlik oluşma ihtimali oldukça yüksektir. ${ }^{13} \mathrm{Bu}$ nedenden dolayı çalışmamızda, kanal şekillendirmesinin ilk aşaması olan rehber yol oluşturulması için kullanılan PathFile ve ProGlider NiTi döner eğeleri ve manuel eğe sistemleri kanal şekillendirme etkinliklerini incelemeyi amaçladık.

Eğelerin kanal şekillendirme etkinliğinin değerlendirilmesi için çekilmiş dişler ya da şeffaf akrilik bloklar kullanılabilmektedir. Çekilmiş dişlerin sahip olduğu anatomik varyasyonlar, grupların standardizasyonunu zorlaştırmakta ve gruplar arasında sonuçlarının karşılaştırılmasını zorlaştırabilmektedir. ${ }^{14}$ Rezin blokların ise en büyük dezavantajı sertliklerinin doğal diş sertliği ile aynı olmamasıdır. ${ }^{15}$ Aynı zamanda rezin bloklarda döner eğe kullanımı sırasında oluşan ISI, rezin materyalinin yumuşamasına neden olabilmektedir. ${ }^{16}$ Tüm bu dezavantajlarının yanında yapay kanal kullanımı, örneklerin sahip olduğu kanal genişliği, kanal kurvatür yarıçapı, açısı ve derecesinin standardizasyonunu sağlamaktadır. Preperasyon öncesi ve sonrası fotoğraflar üst üste çakıştırılması, dijital ortamda kanalın herhangi bir noktasındaki sapmanın analiz edilmesini sağlamaktadır. ${ }^{17} \mathrm{Bu}$ nedenlerden dolayı çaıışmamızda standart yapay rezin bloklar kullanılmıştır.

Çalışmamızın sonuçlarına göre test edilen PathFile, ProGlider NiTi ve manuel eğelerin 5 farklı ölçüm noktasında göstermiş olduğu sapmalar arasında istatistiksel olarak fark bulunmamıştır $(P>0,05)$. Bu nedenden dolayı çalışmamızın sıfır hipotezi kabul edilmiştir. Ayrıca çalışmamız sonuçlarına göre ölçüm noktalarının iç ve dış kısımlarında görülen farklı miktarlarda rezin uzaklaştırılması test edilen eğelerin sahip olduğu farklı yatay kesit, koniklik açısı ve apikal çaptan kaynaklanabilir. ${ }^{18}$ ProGlider grubunda, kanal girişinde ve kanal girişinin yarısında uzaklaştırılan rezin miktarı diğer gruplardan fazladır. $\mathrm{Bu}$ durumun ProGlider eğesinin şaftı boyunca \%2'den \%8'e kadar değişen koniklik açısına sahip olması ve ayrıca eğenin yatay kesitinin diğer eğelerden daha büyük olması nedeniyle daha fazla rezin uzaklaştırmasından kaynaklanmış olabileceğini düşünmekteyiz. Berutti ve ark., da 
çalışmalarında ProGlider eğesinin değişen koniklik açıları nedeniyle PathFile eğelerinden koronal ve orta üçlüde daha fazla genişletme sağladığını bildirmişlerdir. ${ }^{19}$

Kurvatür sonu ve apikal noktasında ise iç ve dış kısımdan PathFile eğe grubu diğer gruplara göre daha fazla rezin uzaklaştırmıştır. Bu sonucun nedeni olarak, PathFile 3 numaralı eğenin DO noktasındaki çapın $(0,19 \mathrm{~mm})$, ProGlider eğesinin D0 noktasındaki çapından $(0,16 \mathrm{~mm})$ daha büyük olmasından kaynaklandığını düşünmekteyiz. Manuel eğe grubunda 1 örnekte basamak oluşumu gözlenmiş olup NiTi döner eğe sistemlerinin kullanıldığı diğer gruplarda herhangi bir kanal içi düzensizlik gözlenmemiştir. Berutti ve ark. çalışmalarında PathFile grubunun manuel eğe grubuna göre kanal kurvatüründe daha az sapma oluşturduğu ve rehber yol oluşturma açısından daha güvenli olduğunu bildirmişlerdir. ${ }^{2}$

Kirchhoff ve ark. çalışmalarında, PathFile ve ProGlider eğelerinin benzer apikal transportasyon değerleri ve rehber yol oluşturulması sonucunda benzer hacimsel artış değerleri gösterdiğini bildirmişlerdir. ${ }^{20}$ Preperasyon sonrası elde edilen kanal genişlikleri incelendiğinde de çalışmamızdaki sonuçlara benzer şekilde beş farklı ölçüm noktasında gruplar arasında istatistiksel olarak anlamlı farklılık bulunmamıştır.

Çalışmamızda kullanılan kanalların akrilik bloklardan oluşması ve ölçümlerin 2 boyutlu olarak değerlendirilmesi çalışmamızın sınırlarını oluşturmaktadır.

\section{SONUÇ}

Çalışmamızın sınırları dahilinde test edilen PathFile, ProGlider ve manuel eğelerin 5 farklı ölçüm noktasında göstermiş olduğu sapmalar arasında fark bulunamamıştır.

Taha Özyürek ORCID ID: 0000-0003-3299-3361

Koray YIImaz ORCID ID: 0000-0001-6096-7385 Gülşah Us/u ORCID ID: 0000-0003-3176-1251

\section{KAYNAKLAR}

1. Roland DD, Andelin WE, Browning DF, et al. The effect of preflaring on the rates of separation for 0.04 taper nickel titanium rotary instruments. J Endod 2002;28:543-5.

2. Berutti E, Cantatore G, Castellucci A, et al. Use of nickel-titanium rotary Pathfile to create the glide path: comparison with manual preflaring in simulated root canals. J Endod 2009;35:408-12.

3. Platino PV, Biedma BM, Liebana CR, et al. The influence of a manual glide path on the separation rate of NiTi rotary instruments. J Endod 2005; 31:114-6.

4. Berutti $E$, Negro $A R$, Lendini $M$, et al. Influence of manual preflaring and torque on the failure rate of Protaper rotary instruments. J Endod 2004;30:22830.

5. Jafarzadeh $\mathrm{H}$, Abbott PV. Ledge formation: Review of a great challenge in endodontics. J Endod 2007;33:1155-62.

6. Blum JY, Machtou P, Ruddle C, et al. Analysis of mechanical preparations in extracted teeth using ProTaper rotary instruments: value of the safety quotient. J Endod 2003;29:567-75.

7. Berutti E, Paolino DS, Chiandussi G, Alovisi M, Cantatore G, Castellucci A, Pasqualin D. Root canal anatomy preservation of WaveOne reciprocating files with or without glide path. J Endod 2012;38:101-4.

8. Zanette $F$, Grazziotin-Soares $R$, Flores $M E$, Fontanella VRC, Gavini G, Barletta FB. Apical root canal transportation and remaining dentin thickness associated with ProTaper Universal with and without PathFile. J Endod 2014;40:688-93.

9. Capar ID, Kaval ME, Ertas $\mathrm{H}$, et al. Comparison of the cyclic fatigue resistance of 5 different rotary pathfinding instruments made of conventional nickel-titanium wire, M-wire and controlled memory wire. J Endod 2015;41:535-8.

10. Thompson M, Sidow SJ, Lindsey K, Chuang A, McPherson JC. Evaluation of a new filing system's ability to maintain canal morphology. J Endod 2014;40:867-70.

11. Altunbaş $D$, Akpınar KE, Kuştarcı A. An in vitro study of the effects of different torque values applied to the nickel titanium rotary canal instruments for curved root canal preparation . J Dent Fac Atatürk Uni 2015;25:172-80.

12. Sonntag D, Guntermann A, Kim SK, Stachniss V. Root canal shaping with manual stainless steel files and rotary $\mathrm{Ni}-\mathrm{Ti}$ files performed by students. Int Endod J 2003;36:246-55.

13. Jafarzadeh $\mathrm{H}$, Abbott PV. Ledge formation: review of a great challenge in endodontics. J Endod 2007;33:1155-62. 
14. Calberson FLG, Deroose CAJG, Hommez GMG, De Moor RJG. Shaping ability of ProTaper nickeltitanium files in simulated resin root canals. Int Endod J 2004;37:613-23.

15. Schäfer E, Tepel J, Hoppe W. Properties of endodontic hand instruments used in rotary motion Part 2. instrumentation of curved canals. J Endod 1995;21:493-7.

16. Kum KY, Spängberg L, Cha BY, Il-Young J, SeungJong $L$, Chan-Young L. Shaping ability of three ProFile rotary instrumentation techniques in simulated resin root canals. J Endod 2000;26:71923.

17. Franco V, Fabiani C, Taschieri S, Malentacca A, Bortolin $M$, Del Fabbro $M$. Investigation on the shaping ability of nickel-titanium files when used with a reciprocating motion. J Endod 2011;7:1398401.

18. Altunbas D, Kutuk B, Kustarci A. Shaping ability of reciprocating single-file and full-sequence rotary instrumentation systems in simulated curved canals. Eur J Dent 2015;9:346.

19. Berutti E, Alovisi M, Pastorelli MA, Chiandussi G, Scotti N, Pasqualini D. Energy consumption of ProTaper Next X1 after glide path with PathFiles and ProGlider. J Endod 2014;40:2015-8.

20. Kirchhoff AL, Chu R, Mello I, Garzon ADP, dos Santos M, Cunha RS. Glide Path Management with Single-and Multiple-instrument Rotary Systems in Curved Canals: A Micro-Computed Tomographic Study. J Endod 2015;41:1880-3.

\section{Yazışma Adresi}

Araş. Gör. Dr. Taha ÖZYÜREK

Ondokuz Mayıs Üniversitesi,

Diş Hekimliği Fakültesi,

Endodonti Anabilim Dalı,

e-mail: tahaozyurek@hotmail.com

Tel: 03623121919 - 8175 